\title{
Investigation of Vertical Distance between Incisive Papilla and Incisal Edge of Maxillary Central Incisors
}

\author{
M. Ustun Guldaga \\ Fatih Sentut ${ }^{b}$ \\ U. Sebnem Buyukkaplanc
}

\section{ABSTRACT}

Objectives: The aim of the present study was to determine the vertical distance between maxillary central incisors and incisive papilla.

Methods: The vertical distance between incisal edges of maxillary central incisors and the centre of the incisive papilla was measured by a digital caliper on the stone casts that were obtained from dentate subjects.

Results: The mean vertical distance between maxillary central incisors and incisive papilla on the stone casts was $6.70 \pm 0.81 \mathrm{~mm}$. The vertical distance range was $5.51 \mathrm{~mm}$ to $8.89 \mathrm{~mm}$.

Conclusions: The clinical relevance of this study lies in application to complete denture construction. The dentist and laboratory technician can be use the results of this study as a guideline in fabrication of maxillary occlusal rims and in determination of the position of the occlusal plane with the reference of other anatomical landmarks together. However, the wax rim should be modified intraorally to incorporate individual characteristics and the anterior tooth should be arranged on modified wax rim. (Eur J Dent 2008;2:161-166)

Key words: Incisive papilla; Maxillary central incisors; Occlusal plane.

\section{INTRODUCTION}

The maxillary anterior teeth should be positioned as close as possible to the positions originally occupied by natural teeth to achieve a

- a Professor, Department of Prosthodontics, Faculty of Dentistry, Suleyman Demirel University,

Isparta, Turkey.

b Private practice, Oral Health Center, Gaziantep, Turkey.

Assistant Professor, Department of Prosthodontics, Faculty of Dentistry, Suleyman Demirel University, Isparta, Turkey.

- Corresponding author: U. Sebnem Buyukkaplan Suleyman Demirel Universitesi, Dis Hekimligi Fakultesi, Protetik Dis Tedavisi Anabilim Dali, Isparta-Turkey Phone: + 902462113260

Fax: + 902462370607

E-mail: satacamed.sdu.edu.tr natural appearance in making complete dentures. ${ }^{1}$ It is necessary to refer to anatomic landmarks to achieve this goal. ${ }^{2}$ The incisive papilla is a small, pear shaped eminence composed of a pad of fibrous connective tissue overlying bony exit of nasopalatine blood vessels-nerves and one of the significant anatomical landmark in locating maxillary anterior central incisors position in complete denture fabrication procedure. Harper ${ }^{3}$ stated that the incisive papilla was stable that was obtained by caliper measurements on preextraction and post-resorption models of the same cases over seven years. $\mathrm{McGee}^{4}$ notes that the incisive papilla remains in a constant position after tooth loss. Although the shape and the 
localization of the papilla shows a wide range of variation, ${ }^{5-8}$ the centre of the papilla is commonly used as a reference point in denture construction and studies. ${ }^{2-4,9-15}$ When artificial teeth is set in proper positions, which were determined from the incisive papilla, the foundation is correctly laid for natural speech, pleasing appearances and normal function. ${ }^{3}$

The horizontal relationship between incisive papilla and maxillary central incisors has been already investigated by several authors. Harper ${ }^{3}$ suggested that the incisal edges of the maxillary central incisors should be 5 to $8 \mathrm{~mm}$ at the horizontal direction in front of the centre of the papilla. Ortman and $\mathrm{Tsao}^{6}$ stated that the most anterior part of the maxillary central incisors and the posterior of the incisive papilla was 12.45 $\mathrm{mm}$. Also, Grave and Becker ${ }^{16}$ proved this similar measurement as 12 to $13 \mathrm{~mm}$. Many studies showed that incisal edges of the maxillary central incisors were positioned 8 to $10 \mathrm{~mm}$ in front of the centre of the incisive papilla. ${ }^{2,4,6-8,10-20}$ Another anatomical landmark that have been suggested in complete denture construction is pterygomaxillary notch-incisive papilla plane. ${ }^{21} \mathrm{Fu}$ et $\mathrm{al}^{22}$ found that the pterygomaxillary notch-incisive papilla plane tends to be more parallel to the occlusal plane that uses mesio-labial incisal edge of maxillary right central incisor as anterior reference point and mesio-buccal cusp tips of maxillary first or second molars as posterior reference point.

Although, several studies investigated the horizontal relationship between incisive papilla and the maxillary central incisors, ${ }^{2-4,10,11,16,17,20,21,23-25 ~}$ the authors did not find specific information in the literature relative to vertical distance between the incisive papilla and the maxillary central incisors. Thus, the aim of the present study was to determine the vertical distance between the maxillary central incisors and centre of the incisive papilla.

\section{MATERIALS AND METHODS}

Dental student volunteers from Suleyman Demirel University Faculty of Dentistry were solicited by a written announcement to participate in the study. The inclusion criteria were: no restoration and tooth loss on the upper jaw, wellarranged maxillary anterior teeth, no orthodontic treatment, Angle Class I maxillomandibular relationship, no pathology that affects the dentition or the surface texture and shape of teeth, no incisal wear on the dentition and no gummy smile in the subjects. The volunteers were examined by one of the investigators of the study and one hundred volunteers (58 women, 42 men) were selected from the students that have the inclusion criteria with a draw. The ages of the subjects were ranged from 19 to 22 years, with a mean age of $20.37 \pm 1.1$ years.

Upper jaw impressions were taken on the subjects by using stock impression trays (Teknik Dental Rostfrei, Istanbul, Turkeyl and irreversible hydrocolloid impression material (Tulip, Cavex Holland, Haarlem, Holland). In order to correctly register the incisive papilla and reduce soft tissue distortion the impression was made under minimal pressure. The stone casts were obtained using ADA type III dental stone Gilidur, Fachbereich Dental, Ludwigshafen, Germanyl. Each stone cast was trimmed following the same procedures to produce a flat base that was parallel to the occlusal plane lanterior reference point: mesio-labial incisal edge of upper right central incisors; posterior reference points: mesio-buccal cusp tips of upper first molars). Two $\mathrm{mm}$ standard transparent resin plate and a spirit level (Veto, Istanbul, Turkey) were used to achieve the parallelism of the described occlusal plane to the base of the stone casts. Stone casts were numbered randomly for measurements.

The centre of the incisive papilla was found measuring the planar distance between the most anterior and posterior borders of the incisive papilla that was on the median line of the palate using a digital caliper which had a precision level at $0.01 \mathrm{~mm}$ (Mitutoyo Corporation, Tokyo, Japan) (Figure 1) and halving this distance. The midpoints of the incisive papilla were marked on each stone cast (Figure 2).

A digital caliper that was fixed perpendicular to the horizontal bar of a surveyor (Rotaks Dent A.S., Istanbul, Turkeyl was used as a measurement instrument (Figure 3). Stone casts were mounted to the surveyor by the help of a spirit level to obtain a certain level in the horizontal plane. The midpoint of the flat edge panel of the depth caliper was marked with graphite. The flat edge plane of the depth caliper had contacted to the mesial incisal edges of the maxillary central incisors and the midpoint of the flat edge plane of the depth caliper 
was matched with the midpoint of the maxillary central incisors (Figure 4). The pin of the depth caliper was touched to the midpoint mark of the incisive papilla. The mounted casts were moved by sliding and the first measurement accepted as a starting point. Measurement results of each stone casts were recorded as millimeters.

The measurements were done by two investigators using the same instrument at two separate times. The average values of two investigators' measurements were calculated and analyzed with SPSS 13.0 for Windows (SPSS Inc., Chicago, III, USA).

\section{RESULTS}

The kappa scores for the assessment of intra and inter observer agreement were higher than 0.75 which implies substantial agreement between the observers (Tables 1 and 2). The mean vertical

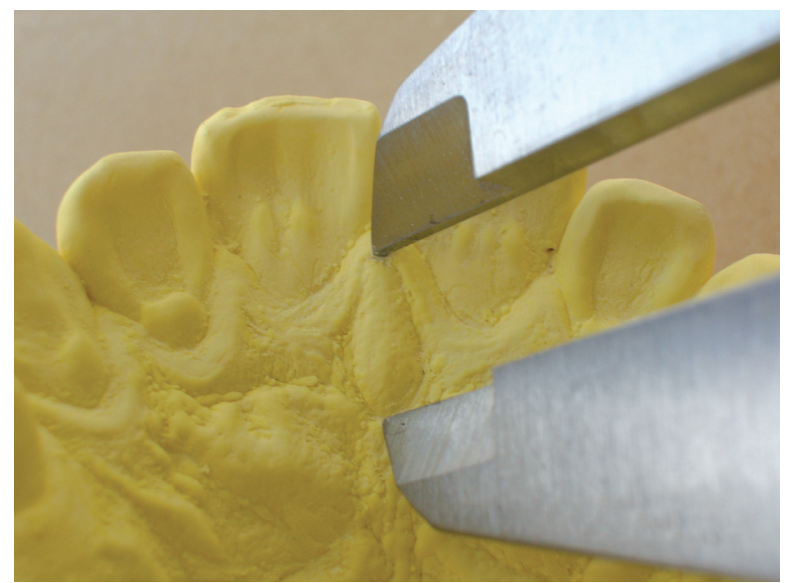

Figure 1. Measurement of the distance between most anterior and posterior borders of the incisive papilla on stone casts.

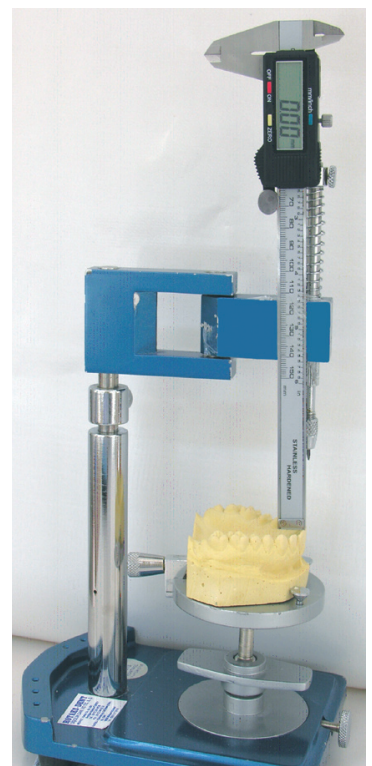

Figure 3. Vertical distance measurement device. distance between maxillary central incisors and midpoint of the incisive papilla on the stone casts was $6.70 \pm 0.81 \mathrm{~mm}$. The vertical distances were ranged from $5.51 \mathrm{~mm}$ to $8.89 \mathrm{~mm}$.

\section{DISCUSSION}

A common average vertical position of the maxillary anterior teeth to the constant landmarks has been found by measuring lots of casts of natural healthy teeth. It is important to orient the stone casts in a standardized manner during measurements so that the results achieved can be applied when artificial teeth are being set in complete denture bases. The occlusal plane is a common reference for mounting stone casts and in general, occlusal plane done parallel to the bases of stone cast in standardize manner. Fu et $\mathrm{al}^{22}$ found the pterygomaxillary notch-incisivepapilla plane (HIP) tends to be parallel to the

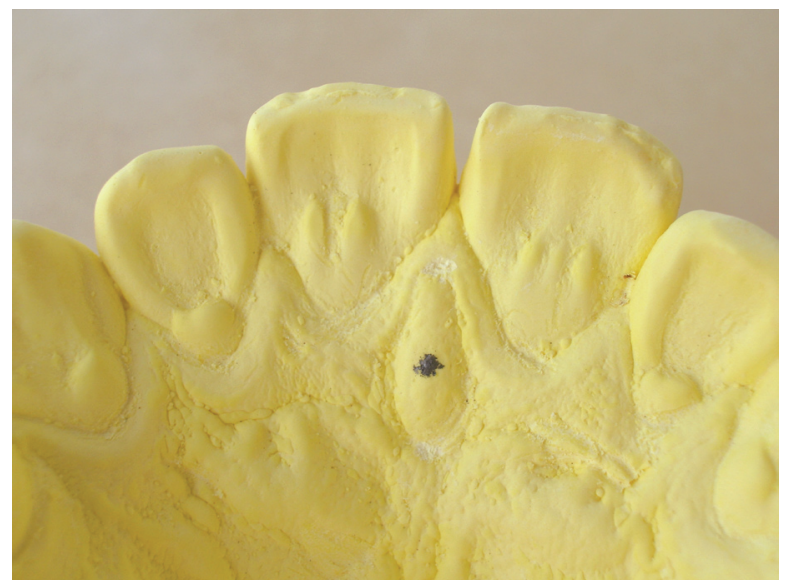

Figure 2. Marked midpoint of the incisive papilla on stone cast.

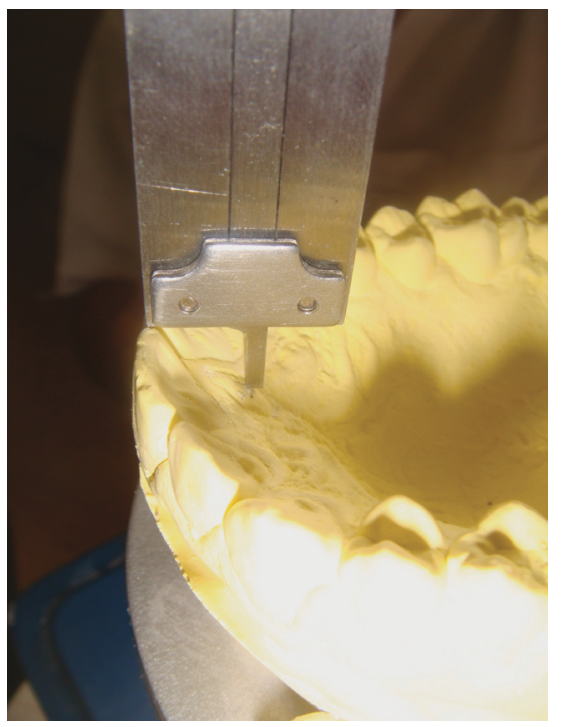

Figure 4. Measurement of the vertical distance between incisive papilla and incisal edge of maxillary central incisors. 
natural occlusal plane that defined as anterior reference point was mesio-labial incisal edge of upper right central incisor and posterior reference points were mesio-buccal cusp tips of upper first or second molars. In the present study, a standard transparent resin sheet was positioned in contact with the maxillary right central incisors and the mesio-buccal cusp tips of first molars to orient the stone cast to the standardized occlusal plane. This occlusal plane orientation was used, for it is more comparable to the pterygomaxillary notchincisive-papilla occlusal plane. ${ }^{22}$

Harper $^{3}$ stated that the incisive papilla is a dependable basis for reproducing the horizontal and vertical position of the maxillary central incisors. Watt ${ }^{9}$ stated that the anterior portion of the maxilla undergoes extensive resorptive changes following tooth removal and the anatomic location of the incisive papilla can be used only as a guide in the setting of denture teeth. Grave ${ }^{16}$ suggested that using the border of the incisive papilla as the part likely to be least affected by the changes in anatomy of the region.

In the previous studies, the midpoint of the incisive papilla has been used as a reference point for tooth arrangement. Most of the previous studies used the midpoint of the incisive papilla as a reference point. 2,4,10-15,25,26 The midpoint of the incisive papilla has also been used as a reference point for tooth arrangement and occlusion rims in contemporary dental practice. Pterygomaxillary notch-incisive-papilla occlusal plane also uses the centre of the incisive papilla as anterior reference point.22 For these reasons; the centre of the incisive papilla was used as a reference point for measurements in the present study.

Ortman and $\mathrm{Tsao}^{6}$ stated that the most anterior part of the maxillary central incisors and the

Table 1. Intra- and inter- observer agreement in measurement of distance between the most anterior and posterior borders of incisive papilla, quantified by Cohen's kappa.

\begin{tabular}{ll}
\hline Kappa Score (K) & \\
\hline Intra-observer agreement (observer 1) & 0.84 \\
Intra-observer agreement (observer 2) & 0.89 \\
Inter-observer agreement & 0.81 \\
\hline
\end{tabular}

$\mathrm{K}<0.40$ poor agreement, $\mathrm{K}=0.41-0.60$ moderate agreement, $\mathrm{K}=0.61-0.80$ substantial agreement, $\mathrm{K}>0.75$ almost perfect agreement. posterior of the incisive papilla was $12.45 \mathrm{~mm}$. Also, Grave and Becker ${ }^{16}$ proved this similar measurement as 12 to $13 \mathrm{~mm}$. Lassila et $\mathrm{al}^{27}$ found measurement of the same distance as $12 \mathrm{~mm}$. The measurement methods of all these studies were in 2-dimensional, however Park et $\mathrm{al}^{28}$ found similar results $(11.96 \pm 1.37)$ in their 3 -dimensional measurement on a virtual model between the maxillary anterior teeth and incisive papilla. The results of these studies that used 2 and 3 dimensional measuring methods show that a sensitive measuring method is reliable and can be repeatable.

Chalsuthipan and Boonsiri29 investigated the relationship between the incisive papilla, maxillary central incisors and canines in Thai population. They analyzed three hundred and sixty selected maxillary models in their study. The authors found that the vertical distance from the most distal point of the incisive papilla to incisal edge of the central incisors was ranged from 6.94 to $7.23 \mathrm{~mm}$ with the mean of $7.08 \mathrm{~mm} .^{29}$ The present study supports the findings of Chalsuthipan and Boonsiri. ${ }^{29}$ The mean value difference between Chalsuthipan and Boonsiri's study ${ }^{29}$ and the present study was 0.38 $\mathrm{mm}$. The mean value variation may be caused by the reference point differences on the incisive papilla because the authors used the most posterior border of the incisive papilla. The most posterior part of incisive papilla is the most far from the occlusal plane and maxillary central incisors.

On the anterior region of the maxilla, the major determiner of the occlusal plane is maxillary central incisors. The vertical relationship between incisive papilla and central incisors can be used in determination of occlusal plane with the reference of other anatomical landmarks together; however the clinical applicability of this relationship in

Table 2. Intra- and inter- observer agreement in measurement of vertical distance between incisive papilla and incisal edge of maxillary central incisors, quantified by Cohen's kappa.

\begin{tabular}{ll}
\hline Kappa Score (K) & \\
\hline Intra-observer agreement (observer 1) & 0.83 \\
Intra-observer agreement (observer 2) & 0.86 \\
Inter-observer agreement & 0.77 \\
\hline
\end{tabular}

$\mathrm{K}<0.40$ poor agreement, $\mathrm{K}=0.41-0.60$ moderate agreement, $\mathrm{K}=0.61-0.80$ substantial agreement, $\mathrm{K}>0.75$ almost perfect agreement. 
complete denture construction needs further investigation.

\section{CONCLUSIONS}

This study investigated the vertical distance between maxillary central incisors and centre of incisive papilla. The clinical relevance of this study lies in application to complete denture construction. The dentist and laboratory technician can be use the results of this study as a guideline in fabrication of maxillary occlusal rims and in determination of the position of the occlusal plane with the reference of other anatomical landmarks together. However, the wax rim should be modified intraorally to incorporate individual characteristics, and the anterior tooth should be arranged on modified wax rim. Also, further investigations are needed in different age, gender, race, dental and skeletal morphology groups.

\section{REFERENCES}

1. LaVere AM, Marcroft KR, Smith RC, Sarka RJ. Denture tooth selection: An analysis of the natural maxillary central incisor compared to the length and width of the face. $J$ Prosthet Dent 1992;67:661-663.

2. Lau GC, Clark RF. The relationship of the incisive papilla to the maxillary central incisors and canine teeth in southern Chinese. J Prosthet Dent 1993;70:86-93.

3. Harper RN. The incisive papilla. J Dent Res 1948;27:661668.

4. McGee GF. Tooth placement and base contour in denture construction. J Prosthet Dent 1960;10:651-657.

5. Watt DM, Likeman PR. Morphological changes in the denture bearing area following the extraction of maxillary teeth. Br Dent J 1974;19:225-235.

6. Ortman HR, Tsao DH. Relationship of the incisive papilla to the maxillary central incisors. J Prosthet Dent 1979;42:492496

7. Klemetti E, Lassila L, Lassila V. Biometric design of complete dentures related to residual ridge resorption. $J$ Prosthet Dent 1996;75:281-284.

8. Likeman PR, Watt DM. Morphological changes in the maxillary denture bearing area. Br Dent J 1974;19:500-503.

9. Watt DM. Tooth positions on complete dentures. J Dent 1978;6:147-160.

10. Schiffman P. Relation of the maxillary canines to the incisive papilla. J Prosthet Dent 1964;14:469-472.

11. Ehrlich J, Gazit E. Relationship of the maxillary central incisors and canines to the incisive papilla. J Oral Rehabil $1975 ; 2: 309-312$
12. Fenton $A H$. Selecting and arranging prosthetic teeth and occlusion for the edentulous patient. In: Eckert. Jacob. Fenton A.H. Mericske-Stern, editors. Prosthodontic treatment for edentulous patients. 12th ed. St. Louis: Mosby; 2004. p. 310.

13. Watt MD. Designing complete dentures. Philadelphia: W.B. Saunders Co.; 1976.

14. Alan Ogden Honorary Curator. Guidelines in Prosthetic and Implant Dentistry. London: Quintessence Publishing; 1996.

15. Huang SJ, Chou TM, Lee HE, Wu YC, Yang YH, Ho CD, Huang PS. Exploring the distance between upper central incisor edge and incisive papilla in Taiwanese population. Taiwan $J$ Oral Health Sci 2004;20:4-10.

16. Grave AM, Becker PJ. Evaluation of the incisive papilla as a guide to anterior tooth position. J Prosthet Dent 1987;57:712714.

17. Hickey JC, Boucher CO, Woelfel JB. Responsibility of dentists in complete denture construction. J Prosthet Dent 1962;12:637-653.

18. Martone AL. The phenomenon of function in complete denture prosthodontics. J Prosthet Dent 1963;13:204-228.

19. Murray CG. Anterior tooth positions in prosthodontics. Aust Dent $J 1977 ; 22: 113-119$.

20. Mavroskoufis F, Ritchie GM. Nasal width and incisive papilla as guides for the selection and arrangement of maxillary anterior teeth. J Prosthet Dent 1981;45:592-597.

21. Cooperman HN. HIP plane of occlusion in oral diagnosis. Dent Surv 1975;51:60-62.

22. Fu PS, Hung CC, Hong JM, Wang JC. Three-dimensional analysis of the occlusal plane related to the hamularincisive-papilla occlusal plane in young adults. $J$ Oral Rehabil 2007;34:136-140.

23. Kharat DU, Madan RS. An investigation into the distance between incisive papilla and incisal edge of maxillary central incisor. J Indian Dent Assoc 1984;56:425-428.

24. Mersel A, Ehrlich J. Connection between incisive papilla, central incisor and rugae canina. Quintessence Int 1981;12:1327-1329.

25. Fu PS, Hung CC, Hong JM, Wang JC, Tsai CF, Wu YM. Three-dimensional relationship of the maxillary anterior teeth to the incisive papilla in young adults. Kaohsiung J Med Sci 2007;23:519-525.

26. Huang SJ, Chou TM, Lee HE, Wu YC, Yang YH, Ho CD, Huang PS. Exploring the distance between upper central incisor edge and incisive papilla in Taiwanese population. Taiwan $J$ Oral Med Health Sci 2004;20:4-10.

27. Lassila LV, Klemetti E, Lassila VP. Position of teeth on the edentulous atrophic maxilla. J Oral Rehabil 2001;28:267272. 
$\square$ Incisive papilla and maxillary central incisors

28. ParkYS, LeeSP,PaikKS. Thethree-dimensional relationship on a virtual model between the maxillary anterior teeth and incisive papilla. J Prosthet Dent 2007;98:312-318.

29. Chalsuthipan S, Boonsiri I. Relationship of central incisor and canine to incisive papilla. Chulalongkorn University Dental Journal 1993;16:29-40 